\title{
Can the development of atrial fibrillation in patients with ischemic heart failure with low ejection fraction be predicted?
}

\author{
(1) Seref Alpsoy, ${ }^{1}$ (i) Kubilay Erselcan, ${ }^{2}$ (i) Aydin Akyuz, ${ }^{1}$ (i) Demet Ozkaramanli Gur, ${ }^{1}$ (i) Sahin Topuz, ${ }^{1}$ \\ (1) Birol Topcu, ${ }^{3}$ (1) Niyazi Guler ${ }^{1}$ \\ ${ }^{1}$ Department of Cardiology, Namik Kemal University Faculty of Medicine, Tekirdag, Turkey \\ 2Department Cardiology, Tekirdag State Hospital, Tekirdag, Turkey \\ ${ }^{3}$ Department of Statistics, Namik Kemal University, Tekirdag, Turkey
}

\begin{abstract}
OBJECTIVE: Our aim is to determine the triggering factors of paroxysmal atrial fibrillation (PAF) in ischemic heart failure (HF) patients with low ejection fraction (EF).

METHODS: Sixty patients were included in this study. Echocardiography and 24-hours Holter monitoring were performed after measurement of serum NT-pro BNP concentration. The patients were classified into two groups concerning the occurrence of PAF on Holter recordings. Biochemical and echocardiographic parameters of patients with and without PAF were compared.

RESULTS: PAF was detected in $28(46 \%)$ patients. Patients with PAF demonstrated higher NT-pro BNP levels, mitral and aortic regurgitation velocities, E/A, E/E', pulmonary capillary wedge pressure, pulmonary artery systolic pressure, left atrial volume and volume indices. NT-pro BNP was established as the predictor of PAF ( $\mathrm{OR}=1.23,95 \% \mathrm{CI}: 1.08-1.42 ; \mathrm{p}=0.001)$. ROC analysis showed an NT-pro BNP value of $2188 \mathrm{pg} / \mathrm{mL}$ as cut-off value with $68 \%$ sensitivity and $84 \%$ specificity [Area under the ROC curve (AUC) $=0.826$, CI 95\%: 0.724-0.927; $p<0.001$ ].

CONCLUSION: The triggering factors for AF are increased intracardiac pressures, left atrial dilatation and increased wall tension. As an indicator of increased wall tension, elevated levels of NT-pro BNP predict the development of PAF.

Keywords: Atrial fibrillation; heart failure; ischemic; low ejection fraction.

Cite this article as: Alpsoy S, Erselcan K, Akyuz A, Ozkaramanli Gur D, Topuz S, Topcu B, et al. Can the development of atrial fibrillation in patients with ischemic heart failure with low ejection fraction be predicted? North Clin Istanb 2020;7(1):18-24.
\end{abstract}

$\mathrm{T}$ he incidence of heart failure (HF) increases with the aging population [1]. Despite novel treatment strategies, $\mathrm{HF}$ is a concerning health issue with high mortality and morbidity rates [2]. Atrial fibrillation (AF) is the most common arrhythmia in HF and is associated with worsening symptoms and a high incidence of thromboembolic complications such as stroke [3-5]. Paroxysmal AF (PAF) carries the same risk of ischemic stroke as permanent $\mathrm{AF}[6]$.
The prevalence of AF is underestimated due to unrecognized episodes of asymptomatic PAF [1]. According to the Framingham study, HF increases the risk of new-onset AF by 4.5 and 5.9 fold in males and females, respectively [7]. In addition to increasing all-cause mortality, AF adversely affects the prognosis of HF due to thromboembolic complications and worsening cardiac function [1-4]. In the COMET trial, the onset of AF was identified as an independent predictor of all-cause

Received: June 10, 2018 Accepted: February 14, 2019 Online: October 08, 2019

Correspondence: Dr. Seref ALPSOY. Namık Kemal Universitesi Tip Fakultesi, Kardiyoloji Anabilim Dali, Tekirdag, Turkey. Tel: +905325844454 e-mail: serefalpsoy@hotmail.com

(c) Copyright 2020 by Istanbul Provincial Directorate of Health - Available online at www.northclinist.com 
mortality in HF [8]. Moreover, new-onset AF was found to be an independent predictor of the combined endpoint of death and hospitalization [9]. Similarly, paroxysmal, but not persistent AF, was a predictor of re-hospitalization in HF [10]. Consequently, it is important to identify the factors that cause AF in patients with HF and, if possible, to prevent them.

Factors leading to AF in individuals with normal cardiac function have widely been investigated and important information has been obtained in this regard [1113]. Since most episodes of AF in HF are not recognized due to a lack of symptoms, it is difficult to estimate the exact frequency of AF in HF. Although the majority of patients with HF have predisposing factors, such as diabetes, hypertension, coronary artery disease, left atrial dilation, increased cardiac volume and pressures, some patients maintain the sinus rhythm. However, it is not clear which patients with HF develop PAF. The present study aims to investigate the factors affecting the development of PAF in HF patients.

\section{MATERIALS AND METHODS}

Between January and May 2017, 60 consecutive patients with systolic HF and sinus rhythm were included in this study. All patients had decreased ejection fraction $(\mathrm{EF}<40 \%)$ due to coronary artery disease and the New York Heart Association (NYHA) functional capacity of 2-4 symptoms. The median age of the patients was $66(30-75)$ years, and 30 patients (50\%) were male. The patients with the previous history of $\mathrm{AF}$, antiarrhythmic medication use, structural valve disease, liver, kidney and thyroid dysfunction, and patients with HF with preserved EF were excluded friom this study. Permission and approval were obtained from the local Ethics committee and patient recruitment started after obtaining written consent from each patient. Thirty-five patients had an anterior myocardial infarction, 25 patients had an anterior and inferior myocardial infarction, 29 patients had undergone coronary artery bypass grafting operation, while 31 patients had undergone previous stent implantation.

Serum NT-pro BNP concentration was determined using Elecsys proBNP sandwich immunoassay (Elecsys 2010, Roche Diagnostics). The analytical range was between 5 to $35000 \mathrm{pg} / \mathrm{mL}$. Variation coefficients of NTpro BNP in the low and high ranges were reported as $4.8 \%$ and $2.7 \%$, respectively.
All echocardiographic measurements were performed concerning the recommendations of current guidelines using the GE-Vingmed Vivid S6 system (GE Vingmed Ultrasound AS, Horten, Norway) and M4S-RS (1.53.6 $\mathrm{MHz}$ ) sector probe. The diameters of the left ventricle (LV) and left atrium (LA) and wall thicknesses were measured according to established standards. The modified Simpson method was used to calculate the left ventricular EF [14]. Left atrial volume (LAV) was calculated by the biplane area-length method and then indexed to body surface area to find the left atrial volume index (LAVI) [15]. Aortic, mitral and tricuspid regurgitation velocities were determined by continuous-wave Doppler echocardiography, and estimated pulmonary artery systolic pressure (PASP) was calculated. Early (E) and late (A) diastolic mitral flow velocities were measured using pulse wave Doppler echocardiography. Mitral annular septal (E' septal) and lateral (E' lateral) velocities were measured using tissue Doppler imaging. Pulmonary capillary wedge pressure (PCWP) was calculated using the Nagueh formula $\left[(\mathrm{PCWP})=1.24\left(\mathrm{E} / \mathrm{E}^{\prime}\right)+1.9\left(\mathrm{E}^{\prime}=\mathrm{E}^{\prime}\right.\right.$ lateral/2+E' septal/2)] [16].

24-hours rhythm Holter analysis was then performed in every patient using a three-channel ambulatory recorder (MT-200, Schiller A.G, Baar, Switzerland). The Holter study was evaluated if it was free of artificial interference. The average heart rates and the occurrence of AF were recorded. PAF was defined as a rhythm with irregular R-R intervals with no $\mathrm{p}$ waves, lasting for 30 seconds or longer [4]. Patients who did not have PAF were also followed by a second rhythm Holter analysis after a week to confirm the absence of PAF. Patients were categorized into "HF with PAF" and "HF without PAF" groups according to ECG Holter data.

\section{Statistical Analysis}

For statistical analysis, IBM SPSS Advanced Statistics 22.0 (Program number: 5725-A54) program was used. The distribution of the data was determined using the Shapiro-Wilk test. Normally distributed variables were presented as "mean \pm standard deviation", non-normally distributed variables were presented as median ( $\mathrm{min}-$ max), and categorical variables as "number (percentage)". The independent samples test-test was used to compare normally distributed variables, and the Mann-Whitney $\mathrm{U}$ test was used to compare non-normal distributed variables. The categorical variables were analyzed using the Chi-square test. Spearman rank correlation analysis was 
TABLE 1. Comparison of demographic, biochemical and echocardiographic characteristics of the study population with and without atrial fibrillation

\begin{tabular}{|c|c|c|c|c|}
\hline & Total $(n=60)$ & $\operatorname{PAF}(+)[n=28]$ & $\operatorname{PAF}(-)[n=32]$ & $\mathrm{p}$ \\
\hline Age (years) & 66 & 66 & 66 & 0.700 \\
\hline Gender (male) & 30 & 13 & 17 & 0.605 \\
\hline BMI $\left(\mathrm{kg} / \mathrm{m}^{2}\right)$ & $29.12 \pm 5.18$ & $29.12 \pm 5.18$ & $30.92 \pm 5.09$ & 0.183 \\
\hline DM & 27 & 14 & 13 & 0.466 \\
\hline HT & 29 & 15 & 14 & 0.448 \\
\hline FC (NYHA Class) & 3 & 3 & 2 & 0.024 \\
\hline $\mathrm{CHA}_{2} \mathrm{DS}_{2}$-VASc score & 3 & 3 & 3.00 & 0.799 \\
\hline Beta Blocker use & 55 & 26 & 29 & 0.755 \\
\hline ACEI/ARB use & 48 & 21 & 27 & 0.365 \\
\hline MRA use & 45 & 21 & 24 & 1.000 \\
\hline Ivabradin use & 17 & 9 & 8 & 0.540 \\
\hline Digoxin use & 11 & 6 & 5 & 0.562 \\
\hline Diüretic use & 47 & 22 & 25 & 0.967 \\
\hline SBP (mmHg) & $119.40 \pm 23.88$ & $115.50 \pm 21.22$ & $122.81 \pm 25.84$ & 0.240 \\
\hline $\mathrm{DBP}(\mathrm{mmHg})$ & $70.32 \pm 14.61$ & $66.96 \pm 14.09$ & $73.25 \pm 14.63$ & 0.097 \\
\hline Heart rate (beats/min) & 80 & 78 & 81 & 0.987 \\
\hline Hemoglobin (gr/dl) & 14 & 14 & 14 & 0.650 \\
\hline Creatinin (mg/dl) & 1.04 & 1 & 1 & 0.331 \\
\hline NT-proBNP (pg/mL) & 1933.5 & 2499 & 1501 & $<0.001$ \\
\hline LVEDD (cm) & $69.08 \pm 4.2$ & $69.2 \pm 4.7$ & $68.8 \pm 4.7$ & 0.839 \\
\hline LVESD (cm) & $59.6 \pm 4.7$ & $60.5 \pm 2.7$ & $58.9 \pm 5.8$ & 0.94 \\
\hline LVEF (\%) & 31.50 & 30.5 & 32 & 0.392 \\
\hline MR velocity $(\mathrm{m} / \mathrm{s})$ & 1.5 & 2.56 & 1.14 & $<0.001$ \\
\hline AR velocity $(\mathrm{m} / \mathrm{s})$ & 0.9 & 1.03 & 0.78 & 0.002 \\
\hline$E / A$ & $1.67 \pm 1.01$ & $2.5 \pm 1$ & $1.4 \pm 0.6$ & $<0.001$ \\
\hline$E / E^{\prime}$ & $14 \pm 10.5$ & $20.4 \pm 12$ & $8.6 \pm 4$ & $<0.001$ \\
\hline PASP (mmHg) & $43 \pm 13$ & $54.3 \pm 9.3$ & $33 \pm 4.6$ & $<0.001$ \\
\hline PCWP (mmHg) & $15.7 \pm 6$ & $19.9 \pm 4.3$ & $12 \pm 4.8$ & $<0.001$ \\
\hline LAV (ml) & $74.8 \pm 26.9$ & $84.8 \pm 30.6$ & $66 \pm 19.8$ & 0.006 \\
\hline LAVI $\left(\mathrm{ml} / \mathrm{m}^{2}\right)$ & $38 \pm 13.9$ & $43.6 \pm 16$ & $33 \pm 9.3$ & 0.002 \\
\hline
\end{tabular}

Chi-square test for dichotomous variables, Independent-samples $t$ test for continuous variables, Mann-Whitney $\mathrm{U}$ test for nonparametric variables. ACEI: Angiotensin converting enzyme inhibitor; AF: Atrial fibrillation; ALT: Alanine transaminase; ARB: Angiotensin reseptör blocker; AST: Aspartate transaminase; AR: Aortic regurgitation; BMI: Body mass index; $\mathrm{CHA}_{2} \mathrm{DS}_{2}$-VASc score, cardiac failure, hypertension, age, diabet, stroke, vascular dsease, sex category; DBP: Diastolic blood pressure; DM: Diabetes mellitus; $E / A$, ratio of early diastolic mitral inflow velocity to late diastolic mitral inflow velocity; $E / E$, of early diastolic mitral inflow velocity to early diastolic mitral annular velocity; FC: Functional capacity; LVEF: Left ventricle ejection fraction; FC: Functional capacity; HT: Hypertension; LAV: Left atrium volume; LAVI: Left atrium volume index; LVEDD: Left ventricle end diastolic diameter; LVESD: Left ventricle end diastolic diameter; MRA: Mineralocorticoid receptor antagonist; MR: Mitral regurgitation; NT-proBNP: N-terminal pro-B-type natriuretic peptide; NYHA: New York Heart Association; fT4: Free thyroxine; PASP: Pulmonary artery systolic pressure; PCWP: Pulmonary capillary wedge pressure; SBP: Systolic blood pressure.

used to determine the relationship between NT-pro BNP and echocardipgraphic variables. Univariate and Multivariate Logistic Regression analyses were performed to identify the predictors of PAF. Receiver Operator Characteristics Curve (ROC) analysis was performed to find cut-off values of predictors for PAF. A p-value of $<0.05$ was considered significant for all analyzes.

\section{RESULTS}

The incidence of PAF in 60 patients with low EF was $46 \%$ $(\mathrm{n}=28]$. The demographic, biochemical and echocardiographic characteristics of the patients are shown in Table 1. There was no significant difference ( $p>0.05$ for all; Table 1) when patients with and without PAF were com- 
TABLE 2. Spearman rank correlation analysis between NTproBNP level and echocardiographic parameters

\begin{tabular}{lcc} 
& \multicolumn{2}{c}{ NT-proBNP } \\
\cline { 2 - 3 } & $\rho$ & $\mathrm{p}$ \\
\hline Mitral regurgitation velocity & 0.418 & $\mathbf{0 . 0 0 1}$ \\
Aortic regurgitation velocity & 0.360 & $\mathbf{0 . 0 0 5}$ \\
E/A & 0.443 & $\mathbf{< 0 . 0 0 1}$ \\
E/E' & 0.488 & $\mathbf{< 0 . 0 0 1}$ \\
Pulmonary artery systolic pressure & 0.496 & $<\mathbf{0 . 0 0 1}$ \\
Pulmonary capillary wedge pressure & 0.488 & $<\mathbf{0 . 0 0 1}$ \\
Left atrial volume & 0.442 & $\mathbf{< 0 . 0 0 1}$ \\
Left atrial volume index & 0.475 & $\mathbf{< 0 . 0 0 1}$ \\
\hline
\end{tabular}

E/A: Ratio of early diastolic mitral inflow velocity to late diastolic mitral inflow velocity; $E / E^{\prime}$ : Ratio of early diastolic mitral inflow velocity to early diastolic mitral annular velocity; NT-proBNP: N-terminal pro-B-type natriuretic peptide.

pared concerning age, sex, body mass index, CHA2DS2VASc score, comorbid diseases, drugs used (beta-blocker, angiotensin-converting enzyme inhibitor/angiotensin receptor blocker, mineralocorticoid receptor antagonist, ivabradine, digoxin, diuretic), systolic and diastolic blood pressures, heart rate, left ventricular dimensions, LVEF, hemoglobin, urea, creatinine, alanine transaminase, aspartate transaminase, thyroid-stimulating hormone, free thyroxine values.

Functional capacity (NYHA class) [3 (2-4) vs 2 (2-4); p=0.024], NT-pro BNP [2499 (1426-9791) vs. $1501(878-3794) \mathrm{pg} / \mathrm{mL} ; \mathrm{p}<0.001]$, mitral regurgitation velocity $[2.56(1.4-4.6)$ vs $1.14(0.46-2) \mathrm{m} /$ sec; $\mathrm{p}<0.001]$, aortic regurgitation end-diastolic velocity $[1.03(0.36-2.6)$ vs $0.78(0.4-1.5) \mathrm{m} / \mathrm{sec}), \mathrm{E} / \mathrm{A}(2.5 \pm 1$ vs $1.4 \pm 0.6 ; \mathrm{p}<0.001), \mathrm{E} / \mathrm{E}^{\prime}(20.4 \pm 12$ vs. $8.6 \pm 4, \mathrm{p}<0.001)$, PASP [54.3 \pm 9.3 vs. $33 \pm 4.6 \mathrm{mmHg} ; \mathrm{p}<0.001]$, PCWP $[19.9 \pm 4.3$ vs. $12 \pm 4.8 \mathrm{mmHg} ; \mathrm{p}<0.001], \mathrm{LAV}[84.8 \pm 30.6$ vs. $66 \pm 19.8 \mathrm{ml} ; \mathrm{p}=0.006]$ and LAVI [ $43.6 \pm 16$ vs $33 \pm 9.3$ $\left.\mathrm{ml} / \mathrm{m}^{2} ; \mathrm{p}=0.002\right]$ were found to be higher in the PAF group (Table 1 ).

The correlation analysis performed using Spearman rank test showed that NT-pro BNP concentrations were positively correlated with mitral regurgitation velocity $(\rho=0.418, p=0.001)$, aortic regurgitation end-diastolic velocity $(\rho=0.360, p=0.005), E / A(\rho=0.443, p<0.001)$, E/E' $(\rho=0.488 ; p=0.001), \operatorname{PASP}(\rho=0.496, p=0.001)$, $\operatorname{PCWP}(\rho=0.488, p=0.001), \operatorname{LAV}(\rho=0.442, p=0.001)$, and LAVI $(\rho=0.475 ; p=0.001)$ (Table 2).
TABLE 3. Univariate and multivariate logistic regression analysis for predictors ofparoxysmal atrial fibrillation in patients with heart failure

\begin{tabular}{lcccccccc} 
Variable & \multicolumn{3}{c}{ Univariate } & & \multicolumn{3}{c}{ Multivariate } \\
\cline { 2 - 4 } \cline { 6 - 8 } & OR & CI 95\% & p & & OR & CI 95\% & p \\
\hline NT-proBNP & 1.37 & $1.14-1.63$ & $\mathbf{0 . 0 0 1}$ & 1.23 & $1.08-1.42$ & $\mathbf{0 . 0 0 1}$ \\
E/E' & 0.99 & $0.98-0.99$ & $\mathbf{0 . 0 0 1}$ & & & \\
PCWP & 1.29 & $1.12-1.48$ & $\mathbf{0 . 0 0 1}$ & & & \\
LAV & 1.03 & $1.01-1.05$ & 0.110 & & & \\
LAVI & 1.07 & $1.02-1.12$ & $\mathbf{0 . 0 0 6}$ & & & \\
MR velocity & 1.17 & $0.80-1.68$ & 0.404 & & & \\
AR velocity & 1.48 & $0.05-2.36$ & 0.561 & & & \\
PASP & 1.04 & $0.96-1.12$ & 0.282 & & & \\
E/A & 1.122 & $0.92-1.61$ & 0.157 & & &
\end{tabular}

AR: Aortic regurgitation; E/A: Ratio of early diastolic mitral inflow velocity to late diastolic mitral inflow velocity; $E / E^{\prime}$ : Ratio of early diastolic mitral inflow velocity to early diastolic mitral annular velocity; LAV: Left atrium volume; LAVI: Left atrium volume index; MR: Mitral regurgitation; NT-proBNP: N-terminal proB-type natriuretic peptide; PASP: Pulmonary artery systolic pressure; PCWP: Pulmonary capillary wedge pressure.

The univariate logistic regression analysis performed to define the predictors of PAF showed that NT-pro $\mathrm{BNP}(\mathrm{OR}=1.37$, CI $95 \%=1.14-1.63 ; \mathrm{p}=0.001), \mathrm{E} / \mathrm{E}^{\prime}$ $(\mathrm{OR}=0.99, \mathrm{p}=0.001)$, PCWP $(\mathrm{OR}=1.29$, CI $95 \%$ $=1.12-1.48, \mathrm{p}=0.001)$ and LAVI $(\mathrm{OR}=1.07$, CI $95 \%$ $=1.02-1.12 ; \mathrm{p}=0.006)$ were associated with PAF. In the multivariate logistic regression analysis, however, only NT-pro BNP was an independent predictor of PAF $(\mathrm{OR}=1.23,95 \% \mathrm{CI}: 1.08-1.42, \mathrm{p}=0.001$, Table 3$)$.

ROC analysis showed an NT-pro BNP value of 2188 $\mathrm{pg} / \mathrm{mL}$ as cut-off value with $68 \%$ sensitivity and $84 \%$ specificity [Area under the ROC curve $(\mathrm{AUC})=0.826$, CI 95\%: 0.724-0.927; $\mathrm{p}<0.001$ ] (Fig. 1).

\section{DISCUSSION}

This study investigated the factors affecting the development of AF in ischemic HF with low EF, $46 \%$ of the patients who had PAF episodes. In addition to echocardiography derived parameters, such as LAV, LAVI, $\mathrm{E} / \mathrm{A}$ and $\mathrm{E} / \mathrm{E}$, mitral and aortic regurgitation velocities, PASP, PCWP, NT-pro BNP levels were elevated in the PAF group. Significant correlations were found between NT-pro BNP and parameters such as mitral regurgitation velocity, aortic regurgitation end-diastolic velocity, 


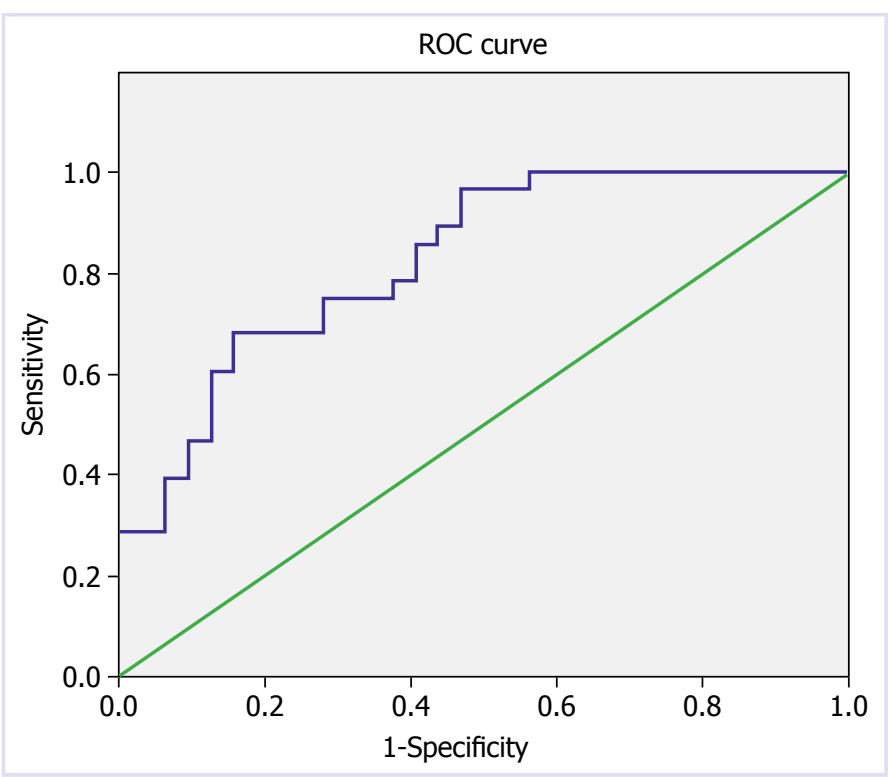

FIGURE 1. Diagnostic value of abnormal NT- pro BNP $>2188 \mathrm{pg} /$ $\mathrm{mL}$ in prediction of paroxysmal atrial fibrillation. Area under the ROC curve (AUC) $=0.826$, CI 95\%: 0.724-0.927; $p<0.001$.

E/A, E/E', PASP, PCWP, LAV and LAVI. Among all variables, high NT-pro BNP concentration was the single independent predictor of the development of AF.

The prevalence of AF in patients with HF is less than $10 \%$ in the NYHA class $1 \mathrm{HF}$ patients, while it increases up to $50 \%$ as the NYHA functional capacity worsens [17]. Multi-center studies [18, 19] of HF with preserved EF reported an increased incidence of AF. In this study, in which the NYHA functional capacity was 3 (2-4), we detected PAF in approximately half of the patients. In accordance with the literature, the functional capacity in the PAF group was worse than the non-PAF group.

Previous studies have shown that an increase in left atrial diameter increases the incidence [20-24], recurrence, and the frequency of $\mathrm{AF}$, parallel to an increase in the risk of stroke [23]. There is an increase in interstitial fibrosis within the atrial wall in HF, causing impaired conduction, which is the substrate for AF [25]. As a result of atrial remodeling, effective refractory period shortens and the duration of atrial conduction prolongs, increasing the incidence of atrial arrhythmias [26]. In this study, both LAV and LAVI were increased in the PAF group. In HF, neurohormonal impairment and the renin-angiotensin-aldosterone system (RAAS) activation lead to an increase in filling pressures and an increase in afterload. These may bring about an increase in wall tension and fibrosis in the left atrium, leading to the development of conduction abnormalities and onset of AF [27]. In our study, in addition to LAV and LAVI, E/E', mitral, aortic and tricuspid regurgitation velocities and PASP were significantly higher in the PAF-detected group. Increased mitral and aortic regurgitation velocities, left ventricular and left atrial dilatation, pulmonary capillary wedge pressure, tricuspid regurgitation velocity, and increased PASP are inter-related processes that develop in the progression of heart failure. Worsening of these parameters increases the atrial wall stress. Thus, the natriuretic peptide release increases.

The release of the natriuretic peptide in HF facilitates the development of AF, and AF itself triggers the release of natriuretic peptides. Increased wall stress in AF was shown to increase NT-pro BNP levels. Sramko et al. [28] showed that pacing-induced AF increased BNP concentrations in blood samples taken 20 minutes after pacing. Although BNP was correlated with mean LA pressure in sinus rhythm, the correlation disappeared with AF. The authors reported that the natriuretic peptide levels were irrespective of left atrial hemodynamics. In this study, we cannot conclude on the causal relationship between increased NT-pro BNP and AF. However, we can call attention to the level of NT-pro BNP and suggest that levels above $2188 \mathrm{pg} / \mathrm{mL}$ may point patients with a predisposition to developing AF. This is in parallel with previous studies in which NT-pro BNP was found to be an important predictor of AF development, independent of other risk factors [29]. High basal NT-pro BNP values were predictors for AF development after four years [30].

There is both systolic and diastolic dysfunction in HF with low EF. As the systolic and diastolic functions deteriorate, wall tension and natriuretic peptide release increase. PAF potentially arises from interstitial fibrosis, inflammation and ischemia, which is common in ischemic HF. Univariate logistic regression analysis revealed NT-pro BNP, E/E', PCWP and LAVI as the predictors of AF. In the Multivariate regression analysis, however, only NT-pro BNP was independently associated with AF. This implies that echocardiographic parameters of diastolic function and increase in NT-pro $\mathrm{BNP}$ are related through the same mechanism; and that echocardiography derived parameters could not predict AF independent of NT-pro BNP. This also suggests that NT-pro BNP is a well-established indicator of increased wall tension and pressures.

The limitations of this study are the small number of patients, the absence of the cardiac catheterization for 
pressure measurement and the relatively short duration of ECG Holter analysis without follow up. Future studies should focus on examining more parameters in larger patient groups and with longer follow-up periods.

\section{Conclusion}

In ischemic HF and low EF, an increase in cardiac dimension, volume and pressures with higher valve regurgitation velocities lead to an increase in wall tension leading to fibrosis and development of transmission abnormalities, such as initiation and continuation of AF. Our study showed that this could be evidenced by an increase in NT-ProBNP. We suggest that patients with high NTproBNP levels should be monitored closely for PAF and timely need for anticoagulation.

Ethics Committee Approval: The Namik Kemal University Faculty of Medicine Ethics Committee for Non-interventional Clinical Research provided ethics committee approval for this study (Date: December 26, 2016, number: 2016/129/11/10).

Conflict of Interest: No conflict of interest was declared by the authors.

Financial Disclosure: The authors declared that this study has received no financial support.

Authorship Contributions: Concept - SA, KE; Design - SA, KE; Supervision - AA, DOG; Materials - KE, ST; Data collection and/or processing - KE, BT, NG; Analysis and/or interpretation - SA, DOG, BT; Writing - SA; Critical review - AA, DOG.

\section{REFERENCES}

1. Ponikowski P, Voors AA, Anker SD, Bueno H, Cleland JGF, Coats AJS, et al. 2016 ESC Guidelines for the diagnosis and treatment of acute and chronic heart failure: The Task Force for the diagnosis and treatment of acute and chronic heart failure of the European Society of Cardiology (ESC)Developed with the special contribution of the Heart Failure Association (HFA) of the ESC. Eur Heart J 2016;37:2129-200. [CrossRef]

2. Writing Committee Members, Yancy CW, Jessup M, Bozkurt B, Butler J, Casey DE Jr, Drazner MH, et al. 2013 ACCF/AHA guideline for the management of heart failure: a report of the American College of Cardiology Foundation/American Heart Association Task Force on practice guidelines. Circulation 2013;128:e240-327.

3. Fuster V, Rydén LE, Cannom DS, Crijns HJ, Curtis AB, Ellenbogen $\mathrm{KA}$, et al. ACC/AHA/ESC 2006 Guidelines for the Management of Patients with Atrial Fibrillation: a report of the American College of Cardiology/American Heart Association Task Force on Practice Guidelines and the European Society of Cardiology Committee for Practice Guidelines (Writing Committee to Revise the 2001 Guidelines for the Management of Patients With Atrial Fibrillation): developed in collaboration with the European Heart Rhythm Association and the Heart Rhythm Society. Circulation 2006;114:e257-354. [CrossRef]

4. Kirchhof P, Benussi S, Kotecha D, Ahlsson A, Atar D, Casadei B, et al; ESC Scientific Document Group. 2016 ESC Guidelines for the man- agement of atrial fibrillation developed in collaboration with EACTS. Eur Heart J 2016;37:2893-962, [CrossRef]

5. Healey JS, Connolly SJ, Gold MR, Israel CW, Van Gelder IC, Capucci A, et al; ASSERT Investigators. Subclinical atrial fibrillation and the risk of stroke. N Engl J Med 2012;366:120-9. [CrossRef]

6. Zhang C, Kasner SE. Paroxysmal Atrial Fibrillation in Cryptogenic Stroke: an Overlooked Explanation? Curr Atheroscler Rep 2015;17:66.

7. Benjamin EJ, Levy D, Vaziri SM, D'Agostino RB, Belanger AJ, Wolf PA. Independent risk factors for atrial fibrillation in a population-based cohort. The Framingham Heart Study. JAMA 1994;271:840-4. [CrossRef]

8. Swedberg K, Olsson LG, Charlesworth A, Cleland J, Hanrath P, Komajda $M$, et al. Prognostic relevance of atrial fibrillation in patients with chronic heart failure on long-term treatment with beta-blockers: results from COMET. Eur Heart J 2005;26:1303-8. [CrossRef]

9. Corell P, Gustafsson F, Schou M, Markenvard J, Nielsen T, Hildebrandt P. Prevalence and prognostic significance of atrial fibrillation in outpatients with heart failure due to left ventricular systolic dysfunction. Eur J Heart Fail 2007;9:258-65. [CrossRef]

10. Koitabashi T, Inomata T, Niwano S, Nishii M, Takeuchi I, Nakano H, et al. Paroxysmal atrial fibrillation coincident with cardiac decompensation is a predictor of poor prognosis in chronic heart failure. Circ J 2005;69:823-30. [CrossRef]

11. Zacà V, Galderisi M, Mondillo S, Focardi M, Ballo P, Guerrini F. Left atrial enlargement as a predictor of recurrences in lone paroxysmal atrial fibrillation. Can J Cardiol 2007;23:869-72. [CrossRef]

12. Svennberg E, Henriksson P, Engdahl J, Hijazi Z, Al-Khalili F, Friberg $\mathrm{L}$, et al. N-terminal pro B-type natriuretic peptide in systematic screening for atrial fibrillation. Heart 2017;103:1271-7. [CrossRef]

13. Vlachos K, Letsas KP, Korantzopoulos P, Liu T, Georgopoulos S, Bakalakos A, et al. Prediction of atrial fibrillation development and progression: Currentperspectives. World J Cardiol 2016;8:267-76.

14. Lang RM, Badano LP, Mor-Avi V, Afilalo J, Armstrong A, Ernande L, et al. Recommendations for cardiac chamber quantification by echocardiography in adults: an update from the American Society of Echocardiography and the European Association of Cardiovascular Imaging. J Am Soc Echocardiogr 2015;28:1-39.e14. [CrossRef]

15. Ujino K, Barnes ME, Cha SS, Langins AP, Bailey KR, Seward JB, et al. Two-dimensional echocardiographic methods for assessment of left atrial volume. Am J Cardiol 2006;98:1185-8. [CrossRef]

16. Nagueh SF, Middleton KJ, Kopelen HA, Zoghbi WA, Quiñones MA. Doppler tissue imaging: a noninvasive technique for evaluation of left ventricular relaxation and estimation of filling pressures. J Am Coll Cardiol 1997;30:1527-33. [CrossRef]

17. Maisel WH, Stevenson LW. Atrial fibrillation in heart failure: epidemiology, pathophysiology, and rationalefor therapy. Am J Cardiol 2003;91:2D-8D. [CrossRef]

18. Yagawa M, Nagatomo Y, Izumi Y, Mahara K, Tomoike H, Shiraishi $Y$, et al. Effect of Obesity on the Prognostic Impact of Atrial Fibrillation in Heart Failure With Preserved Ejection Fraction. Circ J 2017;81:966-73. [CrossRef]

19. Mountantonakis SE, Grau-Sepulveda MV, Bhatt DL, Hernandez AF, Peterson ED, Fonarow GC. Presence of atrial fibrillation is independently associated with adverse outcomes in patients hospitalized with heart failure: an analysis of get with the guidelines-heart failure. Circ Heart Fail 2012;5:191-201. [CrossRef]

20. Vaziri SM, Larson MG, Benjamin EJ, Levy D. Echocardiographic predictors of nonrheumatic atrial fibrillation. The Framingham Heart Study. Circulation 1994;89:724-30. [CrossRef]

21. Qureshi W, Soliman EZ, Solomon SD, Alonso A, Arking DE, Shah 
A, et al. Risk factors for atrial fibrillation in patients with normal versus dilated left atrium (from the Atherosclerosis Risk in Communities Study). Am J Cardiol 2014;114:1368-72. [CrossRef]

22. Tiwari S, Schirmer H, Jacobsen BK, Hopstock LA, Nyrnes A, Heggelund G, et al. Association between diastolic dysfunction and future atrial fibrillation in the Tromsø Study from 1994 to 2010. Heart 2015;101:1302-8. [CrossRef]

23. Tiwari S, Løchen ML, Jacobsen BK, Hopstock LA, Nyrnes A, Njølstad I, et al. CHA2DS2-VASc score, left atrial size and atrial fibrillation as stroke risk factors in the Tromsø Study. Open Heart 2016;3:e000439.

24. Yoshida K, Ulfarsson M, Oral H, Crawford T, Good E, Jongnarangsin $\mathrm{K}$, et al. Left atrial pressure and dominant frequency of atrial fibrillation in humans. Heart Rhythm 2011;8:181-7. [CrossRef]

25. Li D, Fareh S, Leung TK, Nattel S. Promotion of atrial fibrillation by heart failure in dogs: atrial remodeling of a different sort. Circulation 1999;100:87-95. [CrossRef]

26. Solti F, Vecsey T, Kékesi V, Juhász-Nagy A. The effect of atrial dilatation on the genesis of atrial arrhythmias. Cardiovasc Res 1989;23:882-6. [CrossRef]

27. Kalifa J, Jalife J, Zaitsev AV, Bagwe S, Warren M, Moreno J, et al. Intra-atrial pressure increases rate and organization of waves emanating from the superior pulmonary veins during atrial fibrillation. Circulation 2003;108:668-71. [CrossRef]

28. Sramko M, Wichterle D, Melenovsky V, Franekova J, Clemens M, Fukunaga $M$, et al. Independent effect of atrial fibrillation on natriuretic peptide release. Clin Res Cardiol 2019;108:142-9. [CrossRef]

29. Patton KK, Ellinor PT, Heckbert SR, Christenson RH, DeFilippi C, Gottdiener JS, et al. $\mathrm{N}$-terminal pro-B-type natriuretic peptide is a major predictor of the development of atrial fibrillation: the Cardiovascular Health Study. Circulation 2009;120:1768-74. [CrossRef]

30. Asselbergs FW, van den Berg MP, Bakker SJ, Signorovitch JE, Hillege $\mathrm{HL}$, van Gilst WH, et al. N-terminal pro B-type natriuretic peptide levels predict newly detected atrial fibrillation in a population-based cohort. Neth Heart J 2008;16:73-8. [CrossRef] 